\title{
Structural Imposed Load Analysis of Isotropic Rectangular Plate Carrying a Uniformly Distributed Load Using Refined Shear Plate Theory
}

\author{
${ }^{*}$ Festus C. Onyeka, Chidobere D. Nwa-David, and Emmanuel E. Arinze \\ Department of Civil Engineering, Michael Okpara University of Agriculture, Umudike, Nigeria \\ onyeka.festus@edouniversity.edu.ng | \{nwadavid.chidobere | emmanuel.arinze\}@mouau.edu.ng
}

ORIGINAL RESEARCH ARTICLE

Received: 29-OCT-2021; Reviewed: 13-DEC-2021; Accepted: 20-DEC-2021

http://dx.doi.org/10.46792/fuoyejet.v6i4.719

\begin{abstract}
This presents the static flexural analysis of a three edge simply supported, one support free (SSFS) rectangular plate under uniformly distributed load using a refined shear deformation plate theory. The shear deformation profile used, is in the form of third order. The governing equations were determined by the method of energy variational calculus, to obtain the deflection and shear deformation along the direction of $x$ and $y$ axis. From the formulated expression, the formulars for determination of the critical lateral imposed load of the plate before deflection reaches the specified maximum specified limit and its corresponding critical lateral imposed load before plate reaches an elastic yield stress is established. The study showed that the critical lateral imposed load decreased as the plates span increases, the critical lateral imposed load increased as the plate thickness increases, as the specified thickness of the plate increased, the value of critical lateral imposed load increased and increase in the value of the allowable deflection value required for the analysis of the plate reduced the chances of failure of a structural member. This approach overcomes the challenges of the conventional practice in the structural analysis and design which involves checking of deflection and shear after design; the process which is proved unreliable and time consuming. It is concluded that the values of critical lateral load obtained by this theory achieve accepted transverse shear stress to the depth of the plate variation in predicting the flexural characteristics for an isotropic rectangular SSFS plate. Numerical comparison was conducted to verify and demonstrate the efficiency of the present theory, and they agreed with previous studies. This proved that the present theory is reliable for the analysis of a rectangular plate.
\end{abstract}

Keywords- Allowable deflection, critical imposed load, energy method, plate theories, shear deformation, SSFS rectangular plate

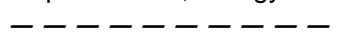

\section{INTRODUCTION}

$\mathrm{P}$ late structures finds its numerous application in aerospace, aeronautic, automotive, and structural engineering. In structural engineering, they can be used as bridge deck, retaining wall for water retaining structures, panel for building slab, ship hull and spacecraft (Okafor and Udeh, 2015). With increasing use of isotropic plate material, the need for an improved approach for load analysis is now desired. In such materials, the transverse shear stresses and strains which were induced by the applied load intensification affect the bending characteristics.

As the load is increased beyond the critical load the lateral deflections increase, until it may fail in other modes such as yielding of the material (Onyeka, 2019). To analyse the bending due to the applied load, the value of the critical load which efficiently causes the plate structure to be unstable as per equilibrium should be developed and evaluated. Since the classical plate theory (CPT) (Okafor and Udeh, 2015; Kirchhoff, 1850), which did not account for transverse shear effects proved unsatisfactory when applied to the isotropic plate analysis with large shear stress, shear deformation theory is obligatory.

\section{${ }^{*}$ Corresponding Author}

Section E- CIVIL ENGINEERING \& RELATED SCIENCES

Can be cited as:

Onyeka F.C., Nwa-David C.D., and Arinze E.E. (2021): Structural Imposed Load Analysis of Isotropic Rectangular Plate Carrying a Uniformly Distributed Load Using Refined Shear Plate Theory, FUOYE Journal of Engineering and Technology (FUOYEJET), 6(4), 414-419. http://dx.doi.org/10.46792/fuoyejet.v6i4.719
Many refined plate theories (RPT) have been developed by many researchers (Ghugal and Sayaad, 2011; Mantari et al., 2012; Ghugal and Kulkarni, 2011; Reddy, 1984; Ghugal and Sayaad, 2012a; Ghugal and Sayaad, 2012b; Onyeka et al., 2018). They include: the trigonometric shear deformation theory (TSDT), exponential shear deformation theory (ESDT) and higher order shear deformation theory (HSDT). These RPT gives more accurate solution in predicting the bending and free vibration behavior of thick isotropic plates under transverse loading as they account for the effect of shear deformation in the analysis.

Ibearugbulem and Onyeka (2020) conducted a study on the bending analysis of thick plate with geometry and with all ends clamped (CCCC) at supports. They used governing equations derived from the Mindlin's plate theory for their analysis. They assumed that the line perpendicular to the mid-plane remains straight after deformation by including the shear correction which is associated to first order shear deformation theory (FSDT). The FSDT which is generally considered to be an improvement of CPT, and also considers transverse shear deformation in the analysis of plates. The FSDT has some limitation as it needs a shear correction factor (Mindlin, 1951; Reisner, 1944; Reisner, 1945). The limitation of CPT and FSDTs led to development of second order and HSDT. HSDT give more accurate analysis results and also put transverse shear deformation into consideration by avoiding shear correction factors (Sayyad et al., 2013; Sayyad and Ghugal, 2012; Ezeh et al., 2018).

Ezeh et al., (2018) and Gwarah (2019) developed a refined plate theory that negates the use of shear correction factor and applied to thick rectangular plate that is clamped at 
the first three edges and the remaining edge simply supported (CCCS) and thick rectangular plate that is free at one edge and the other three edges simply supported (SSFS). They used polynomial displacement function in their derivation of governing differential equation, while Ghugal and Sayaad (2011), Mantari et al. (2012), Ghugal and Kulkarni (2011) applied TSDT which includes shear deformation effect in their plate analysis. The results they obtained were satisfactory results when compared with results from other studies, their work did not analyse the load (critical load) which causes the structure to deflect or crack. The results obtained using the above theory shows slight errors in predicting responses of the lateral load on the structures. This is quite expected because, none of them considered using an exact displacement function derived from the governing equation rather they resorted to an assumed deflection function in their analysis which will not yield a reliable result.

Onyeka and Ibearugbulen (2020) showed the extent of flexibility in the use of polynomial displacement rather than trigonometric, hyperbolic and exponential shape functions in the plate analysis, as they discovered that the lather (trigonometric, hyperbolic and exponential) can be very difficult to use in some complex boundary conditions. In the investigation conducted by Onyeka (2019), a polynomial shear deformation theory was used in the analysis of rectangular plates. They obtained the expression for critical lateral load in predicting responses of the applied load determined to solve bending problem of rectangular plates with all four edges simply supported (SSSS) while Onyeka et al. (2020) got the solution of critical load plates with two adjacent edges clamped (CSCS) and plate clamped with free of support at third edge and the other edges simply supported (SCFS) using third order shear deformation theory for rectangular thick plate respectively. They did not evaluate the effect of load that causes deflection in a SSFS plate. Results obtained using the above theory still proven erroneous in predicting responses of the lateral load on the structures as, they did not check the effect of shear stress which may lead to cracking of the plate structure.

The present work unlike the previous works which assumed the displacement function, perform general variation of the total potential energy in order to get a close form (exact) polynomial displacement function from first principle. Furthermore, the critical lateral impose load used in predicting the flexural characteristics for an isotropic rectangular SSFS plate will be determined, a feat previous work did not achieve. In this work, the static bending analysis of an isotropic rectangular plate subjected to uniform distributed transverse loads was presented using polynomial displacement and refined shear deformation theory. This theory, which is based on traditional higher-order shear deformation was applied in a bending analysis of rectangular plate with free support at the third edge and the other three edges simply supported (SSFS) to determine the effect of deflection and shear stress on an isotropic rectangular plate.

\section{Kinematics and Stress-Strain Relationship}

Using the thick plate assumption that, the vertical line that is initially normal to the middle surface of the plate before bending is neither straight nor normal to the middle surface after bending, the basic displacementstress-strain relationship is known to all and not required to mention. They are obtained from the static elastic theory (Onyeka et al., 2019). The total potential energy functional (П) of thick isotropic plate were derived (Onyeka et al., 2018), as:

$$
\begin{aligned}
& \Pi=\frac{E t^{3}}{24\left(1-\mu^{2}\right) a^{4}} \int_{0}^{1} \int_{0}^{1}\left[\mid g_{1} A_{s}^{2}\left(\frac{\partial^{2} h}{\partial R^{2}}\right)^{2}\right. \\
& -2 g_{2} A_{s} A_{x}\left(\frac{\partial^{2} h}{\partial R^{2}}\right)^{2}+g_{3} A_{x}^{2}\left(\frac{\partial^{2} h}{\partial R^{2}}\right)^{2} \\
& +\mid 2 g_{1} \frac{A_{s}^{2}}{\propto^{2}}\left(\frac{\partial^{2} h}{\partial R \partial Q}\right)^{2} \\
& -2 g_{2} \frac{A_{s} A_{x}}{\alpha^{2}}\left(\frac{\partial^{2} h}{\partial R \partial Q}\right)^{2} \\
& -2 g_{2} \frac{A_{s} A_{y}}{\propto^{2}}\left(\frac{\partial^{2} h}{\partial R \partial Q}\right)^{2} \\
& +\left|(1+\mu) g_{3} \frac{A_{x} A_{y}}{\alpha^{2}}\left(\frac{\partial^{2} h}{\partial R \partial Q}\right)^{2}\right| \\
& +\frac{(1-\mu)}{2} \mid g_{3} \frac{A_{x}^{2}}{\alpha^{2}}\left(\frac{\partial^{2} h}{\partial R \partial Q}\right)^{2} \\
& +g_{3} \frac{A_{y}^{2}}{\alpha^{2}}\left(\frac{\partial^{2} h}{\partial R \partial Q}\right)^{2} \\
& +\mid g_{1} \frac{A_{s}{ }^{2}}{\alpha^{4}}\left(\frac{\partial^{2} h}{\partial Q^{2}}\right)^{2}-2 g_{2} \frac{A_{s} A_{y}}{\alpha^{4}}\left(\frac{\partial^{2} h}{\partial Q^{2}}\right)^{2} \\
& +g_{3} \frac{A_{y}^{2}}{\propto^{4}}\left(\frac{\partial^{2} h}{\partial Q^{2}}\right)^{2} \\
& +\mid \frac{(1-\mu)}{2} \rho^{2} g_{4} A_{x}^{2}\left(\frac{\partial h}{\partial R}\right)^{2} \\
& \left.+\frac{(1-\mu)}{2} \cdot \frac{\rho^{2} g_{4} A_{y}{ }^{2}}{\alpha^{2}}\left(\frac{\partial h}{\partial Q}\right)^{2} \mid\right] a b \partial R \partial Q \\
& -\int_{0}^{1} \int_{0}^{1} q A_{s} h a b \partial R \partial Q
\end{aligned}
$$

Let,

$$
\begin{aligned}
& \mathrm{z}=\mathrm{ts} ; \mathrm{x}=\mathrm{aR} \text { and } \mathrm{y}=\mathrm{bQ} \\
& w=A_{s} \cdot h \\
& \theta_{S x}=\left[\frac{d h}{d R}\right]\left[A_{x}\right] \\
& \theta_{s y}=\left[\frac{d h}{d Q}\right]\left[A_{y}\right]
\end{aligned}
$$

Where;

$\mathrm{a}, \mathrm{b}$ and $\mathrm{t}=$ length, breath and thickness of the plate

$\mathrm{R}, \mathrm{Q}$ and s are non-dimensional value of length, breadth and thickness of the plate

Where $\mathrm{q}$ is the uniformly distributed load.

Let the length to breath aspect ratio, $\propto=\frac{b}{a}$

Span to thickness ratio, $\rho=\frac{\mathrm{a}}{\mathrm{t}}$

$\theta_{S x}$ and $\theta_{S y}$ is rotation in $\mathrm{x}$ and $\mathrm{y}$ axis

$h$ is the shape function of the plate

$A_{s}$ is the coefficient of deflection 
$A_{x}$ is the coefficient of shear deformation along $\mathrm{x}$ axis $A_{y}$ is the coefficient of shear deformation along y axis the symbol $\mu$ denotes poison ratio

the symbol $E$ denotes modulus of elasticity of the plate $D=\frac{E t^{3}}{12\left(1-\mu^{2}\right)}$

\section{Governing Energy Equation}

The solution of general governing differential equation which was gotten from the minimization of the total potential energy according to Onyeka et al. (2019) yields the exact deflection function as given in Equation 30 as:

$$
\begin{aligned}
\mathrm{w}=\left(a_{0}+a_{1} R\right. & \left.+\frac{a_{2} R^{2}}{2}+\frac{a_{3} R^{3}}{6}+\frac{R^{4}}{24} F_{a 4}\right) \\
& \times\left(b_{0}+b_{1} Q+\frac{b_{2} Q^{2}}{2}+\frac{b_{3} Q^{3}}{6}+\frac{Q^{4}}{24} F_{b 4}\right. \\
& \left.+\frac{b_{5} Q^{5}}{120}\right)
\end{aligned}
$$

The direct governing equation is obtained by differentiating the potential energy with respect to the $A_{s}$ coefficient of shear deformation with respect to $\mathrm{x}$-axis $A_{x}$ and coefficient of shear deformation with respect to $y$ axis $A_{y}$.

$\frac{\partial \Pi}{\partial A_{s}}=\frac{\partial \Pi}{\partial A_{x}}=\frac{\partial \Pi}{\partial A_{y}}=0$
$\left[\begin{array}{lll}r_{11} & r_{12} & r_{13} \\ r_{21} & r_{22} & r_{23} \\ r_{31} & r_{32} & r_{33}\end{array}\right]\left[\begin{array}{l}A_{s} \\ A_{x} \\ A_{y}\end{array}\right]=\frac{q a^{4}}{D}\left[\begin{array}{c}k_{q} \\ 0 \\ 0\end{array}\right]$

Let:

$T_{2}=\frac{r_{21} \cdot r_{33}-r_{23} \cdot r_{31}}{r_{22} \cdot r_{33}-r_{23} \cdot r_{32}}$ and $T_{3}=\frac{r_{21} \cdot r_{32}-r_{22} \cdot r_{31}}{r_{23} \cdot r_{32}-r_{22} \cdot r_{33}}$

$A_{s}=\frac{12 q a^{4}\left(1-\mu^{2}\right)}{E t^{3}}\left(\frac{k_{q}}{r_{11} T_{1}-r_{12} T_{2}-r_{13} T_{3}}\right)$

$k_{q}=\int_{0}^{1} \int_{0}^{1} h \cdot d R d Q$

\section{Formulation of the Critical lateral ImPOSED LoAD IN THE Rectangular PLATE}

The formulae for calculating the critical imposed load before deflection reaches specified maximum limit, $q_{i w}$ and its corresponding critical lateral imposed load of the plate before plate reaches an elastic yield stress, $q_{i p}$ is developed using equation established from the previous sections. To ensure that the critical lateral load the plate is determined before it reaches yielding (Onyeka and Ibearugbulem, 2020), recall that;

$w=A_{s} \mathrm{~h}<\mathrm{w}_{\mathrm{s}}$

$\frac{12\left(1-\mu^{2}\right) q a^{4}}{E t^{3}} \cdot\left(\frac{k_{q}}{r_{11}-r_{12} T_{2}-r_{13} T_{3}}\right) \cdot \mathrm{h}<\mathrm{w}_{\mathrm{s}}$

where,

$\mathrm{w}_{\mathrm{s}}=$ Allowable deflection

Also,

$q=\gamma+q_{c}=\gamma+q_{s}$

This gives:

$q_{c}<E t^{3} \frac{\mathrm{w}_{\mathrm{a}}\left(r_{11}-r_{12} T_{2}-r_{13} T_{3}\right)}{\left(1-\mu^{2}\right) 12 . k_{q} \cdot \mathrm{h} a^{4}}-\gamma t$

where; $\gamma=$ Self weight of the plate

$q_{c}=$ critical imposed load before deflection reach elastic limit

$q_{s}=$ critical imposed load before plate reach yield point $f y=$ steel characteristic strength

Also, to ensure that the critical lateral load the plate is determined before it reaches yielding; recall that:

$\cap<\mathrm{n}_{0}>\frac{f y^{2}}{E}$

Putting the established Equation of $\cap$ [21] into 20; gives:

$\frac{1}{E}\left[\sigma_{x}{ }^{2}-2 \mu \sigma_{x} \sigma_{y}+{\sigma_{y}}^{2}+2(1+\mu) \tau_{x y}{ }^{2}+2(1+\mu) \tau_{x z}{ }^{2}\right.$

$$
\left.+2(1+\mu) \tau_{y z}^{2}\right]<\frac{f y^{2}}{E}
$$

Therefore, substituting Equations 25 into 21, gives:

$<\frac{f y}{\left[1-2 \mu n_{1}+n_{1}{ }^{2}+2(1+\mu) n_{2}{ }^{2}+2(1+\mu) n_{3}{ }^{2}+2(1+\mu) n_{4}{ }^{2}\right]}$

where,

$\sigma_{x}=\frac{E\left(\varepsilon_{x}+\mu \varepsilon_{y}\right)}{1-\mu^{2}}=\frac{E z}{1-\mu^{2}}\left(\left(\frac{-d^{2} w}{d x^{2}}+\frac{F d \theta_{S x}}{d x}\right)\right.$

$$
\left.+\mu\left(\frac{d^{2} w}{d y^{2}}+\frac{F d \theta_{S x}}{d y}\right)\right)
$$

$$
\begin{array}{r}
\sigma_{y}=n_{1} \sigma_{x}=\frac{E z}{1-\mu^{2}}\left(\left(-\frac{d^{2} w}{d y^{2}}+\frac{F d \theta_{S x}}{d x}\right)\right. \\
\left.+\mu\left(\frac{d^{2} w}{d x^{2}}+\frac{F d \theta_{S x}}{d y}\right)\right)
\end{array}
$$

$$
\begin{gathered}
\tau_{x y}=n_{2} \sigma_{x}=\frac{\gamma_{x y} E}{2(1+\mu)} ; \tau_{x z}=n_{3} \sigma_{x}=\frac{\gamma_{x z} E}{2(1+\mu)} \text { and } \tau_{y z} \\
=n_{4} \sigma_{x}=\frac{\gamma_{y z} E}{2(1+\mu)}
\end{gathered}
$$

By simplifying Equation 19 and 23, the value of $\sigma_{x}$ becomes;

$\sigma_{x}=\frac{q a^{4} E z\left(\frac{d^{2} h}{d R^{2}}+\frac{\mu}{\alpha^{2}} \frac{d^{2} h}{d Q^{2}}\right)}{\left(1-\mu^{2}\right) D \propto^{2}} \cdot\left(\frac{k_{q}}{r_{11} T_{1}-r_{12} T_{2}-r_{13} T_{3}}\right)$

Equate Equation 22 and 26, we get expression for $q$ as:

$q_{s}<\frac{f y t^{3}}{12} \cdot a^{2} \cdot k \cdot z \cdot\left(\frac{d^{2} h}{d R^{2}}+\frac{\mu}{\alpha^{2}} \frac{d^{2} h}{d Q^{2}}\right) \cdot G-\gamma t$

G

$=\sqrt{\left[1-2 \mu n_{1}+n_{1}{ }^{2}+2(1+\mu) n_{2}{ }^{2}+2(1+\mu) n_{3}{ }^{2}+2(1+\mu) n_{4}{ }^{2}\right]}$ the symbol $\sigma_{x}$ denotes stress normal to $\mathrm{x}$ axis the symbol $\sigma_{y}$ denotes stress normal to y axis the symbol $\tau_{x y}$ denotes shear stress along $x-y$ axis the symbol $\tau_{x z}$ denotes shear stress along $x-z$ axis the symbol $\tau_{y z}$ denotes shear stress along $y-z$ axis the symbol $\varepsilon_{x}$ denotes normal strain along $x$ axis the symbol $\varepsilon_{y}$ denotes normal strain along y axis the symbol $\gamma_{x y}$ denotes shear strain along $x-y$ axis the symbol $\gamma_{x z}$ denotes shear strain along $x-z$ axis the symbol $\gamma_{y z}$ denotes shear strain along $y-z$ axis

\section{Numerical Analysis}

The numerical bending analysis of a simply supported rectangular plate carrying a uniformly distributed transverse load will be performed in this section, to obtain the value of the critical lateral load at various aspect 
ratios. A fourth order polynomial displacement function derived from the previous section will be subject to the SSFS boundary condition as presented in the figure 1, to obtain a particular solution of the polynomial deflection equation for the SSFS rectangular plate.

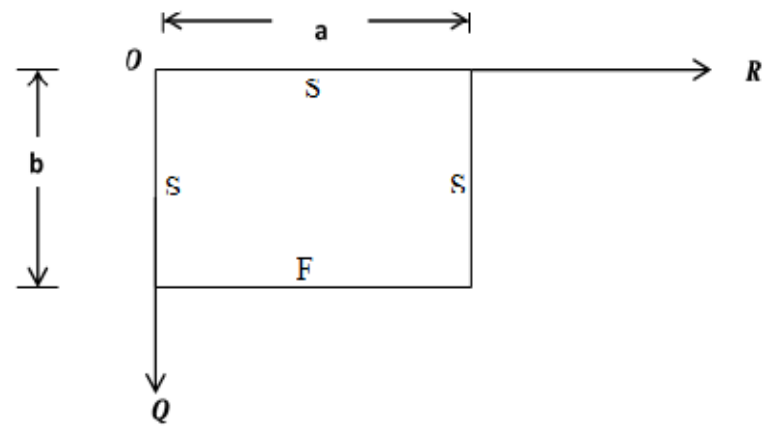

Fig. 1: SSFS rectangular plate under uniformly distributed load

The orthogonal polynomial deflection $\mathrm{w}(\mathrm{x}, \mathrm{y})$ functions that satisfy the boundary conditions for simply - simply supported - free - simply supported rectangular plate boundary conditions are determined. The boundary conditions of the plate in figure 3 are as follows:

At $R=Q=0$; deflection $(w)=0$

At $R=Q=0 ;\left(\right.$ ie. $\frac{d^{2} w}{d R^{2}}$ and $\left.\frac{d^{2} w}{d Q^{2}}\right)=0$

At $R=Q=1 ;(w)=0 ;\left(\right.$ ie $\left.\cdot \frac{d^{2} w}{d Q^{2}}\right)=0$;

At $R=Q=1 ;\left(\right.$ ie $\left.\cdot \frac{d^{2} w}{d R^{2}}\right)=0 ;\left(\right.$ ie $\left.\cdot \frac{d^{3} w}{d Q^{3}}=0\right)$

At, $Q=1 ;$ slope $=\frac{2}{3 b_{5}}\left(\right.$ ie. $\left.\frac{d w}{d Q}=\frac{2}{3 b_{5}}\right)$

Substituting Equations (28-32) into established equation and solving gives the following constants:

$$
\begin{aligned}
& a_{0}=0 ; a_{1}=\frac{F_{a 4}}{24} ; a_{2}=0 ; a_{3}=\frac{-F_{a 4}}{2} \\
& b_{0}=0 ; b_{1}=-\frac{7}{3} b_{5} ; b_{2}=0 ; b_{3}=\frac{b_{5}}{6} ; F_{b 4}=-\frac{2 b_{5}}{3}
\end{aligned}
$$

Substituting the constants of Equation (33) and (34) into established equations gives;

$$
\begin{aligned}
w=\left(F_{a 4} \frac{R}{24}-F_{a 4}\right. & \left.\frac{R^{3}}{12}+F_{a 4} \frac{R^{4}}{24}\right) \\
& \times\left(b_{5} \frac{Q}{52}-b_{5} \frac{Q^{3}}{36}+b_{5} \frac{2 Q^{4}}{72}-b_{5} \frac{Q^{5}}{120}\right)
\end{aligned}
$$

Simplifying Equation (35) which satisfying the boundary conditions of Equation (28-32) gave;

$$
\begin{aligned}
& w=\frac{F_{a 4} \times b_{5}}{8640}\left(R-2 R^{3}+R^{4}\right)\left(7 Q-10 Q^{3}+10 Q^{4}-3 Q^{5}\right) \\
& \quad \text { Recall from that; } \\
& w=A_{s} \cdot h
\end{aligned}
$$

Let the amplitude,

$$
\begin{gathered}
A_{s}=\frac{F_{a 4} \times b_{5}}{8640} \\
\text { And; }
\end{gathered}
$$

$h=\left(R-2 R^{3}+R^{4}\right) \times\left(\frac{7 Q}{3}-\frac{10}{3} Q^{3}+\frac{10}{3} Q^{4}-Q^{5}\right)$

Thus, the polynomial deflection function after satisfying the boundary conditions is:
$w=A_{s}\left(R-2 R^{3}+R^{4}\right) \times\left(\frac{7 Q}{3}-\frac{10}{3} Q^{3}+\frac{10}{3} Q^{4}-Q^{5}\right)$

\section{Results AND Discussion}

Figure 2 and 3, presents the results of the numerical analysis obtained for the SSFS plate with a span of $1000 \mathrm{~mm}, 3000 \mathrm{~mm}$ and $5000 \mathrm{~mm}$, at allowable deflection of $1 \mathrm{~mm}, 3 \mathrm{~mm}$ and $5 \mathrm{~mm}$. The values of specified thickness considered in this study are $5 \mathrm{~mm}, 10 \mathrm{~mm}, 12.5 \mathrm{~mm}$ and $15 \mathrm{~mm}$ at length to width ratio of $1,1.1,1.2,1.3,1.4,1.5,1.6$, 1.8, 1.9 and 2. It is seen from the Table 2, that as the specified thickness $(\mathrm{t})$ of plate increases, the value of critical lateral imposed load $\left(q_{c}\right.$ and $\left.q_{s}\right)$ increases. This implies that an increase in the thickness of the plate ensures safety in the plate structure.

It was observed that, as the allowable deflection $\left(w_{s}\right)$ increases, the value of critical lateral imposed load $\left(q_{c}\right)$, while the critical imposed load $\left(q_{s}\right)$ remains constant. This implies that an increase in the value of the allowable deflection required for the analysis of the plate reduces the chances of failure of the plate structure. Meanwhile, this does not affect critical imposed load $\left(q_{s}\right)$. Furthermore, the results of SSFS plate show that the values of critical lateral imposed load $\mathrm{q}_{i w}$ and $\mathrm{q}_{i p}$ decrease as the length-width ratio increases, this continues until failure occurs. This means that an increase in plate length increases the chance of failure in a plate structure.

From that tables it is observed that the value of the critical load $\left(q_{s}\right)$ is greater than that of the critical load $\left(q_{c}\right)$, this is quite expected because the failure of plate in $\left(q_{s}\right)$ means total failure but that of $\left(q_{c}\right)$ is like a warning requesting maintenance. The positive value of critical lateral imposed load $\left(q_{c}\right.$ and $\left.q_{s}\right)$ reveals that the plate neither fail in $\left(q_{c}\right.$ nor $\left.q_{s}\right)$. This means that the plate structure is safe. Meanwhile, the negative value of critical lateral imposed load $\left(q_{c}\right.$ and $\left.q_{s}\right)$ reveals failure of the plate for the particular aspect ratio into consideration. This means that the plate structure is safe.

The value of critical lateral load of the plate at a span of $1000 \mathrm{~mm}$ for allowable deflection $\left(\mathrm{w}_{\mathrm{s}}\right)$ of $1 \mathrm{~mm}$ through $5 \mathrm{~mm}$ is presented. It is observed that at constant $\mathrm{q}_{s}$, the value of critical load $\left(\mathrm{q}_{c}\right)$ varied between $-0.08727 \mathrm{~N} /$ $\mathrm{mm}$ and $39.038 \mathrm{~N} / \mathrm{mm}$ at specified thickness of $5 \mathrm{~mm}$ and $15 \mathrm{~mm}$ (1 $\mathrm{mm}$ and $5 \mathrm{~mm}$ allowable deflection) being the lowest and highest value respectively. The positive value of critical lateral imposed load $\left(q_{s}\right)$ reveals that the plate does not fail in $\mathrm{q}_{s}$ and its value is not affected by the change in the allowable deflection and thickness of the plate, but only affected by the ratio of the length and breadth of the plate. Meanwhile, it is shown that failure of critical lateral imposed load $\left(\mathrm{q}_{c}\right)$ only occur at thickness of $5 \mathrm{~mm}$ which is between length to width ratio of $1,1.1,1.2,1.3,1.4,1.5,1.6,1.8,1.9$ and 2 with value of $0.0873 \mathrm{~N} / \mathrm{mm},-0.1071 \mathrm{~N} / \mathrm{mm}, 0.1218 \mathrm{~N} / \mathrm{mm},-0.1330$ $\mathrm{N} / \mathrm{mm},-1418 \mathrm{~N} / \mathrm{mm},-1488 \mathrm{~N} / \mathrm{mm},-0.1545 \mathrm{~N} / \mathrm{mm},-0.1592$ $\mathrm{N} / \mathrm{mm},-0.11630 \mathrm{~N} / \mathrm{mm},-0.1663 \mathrm{~N} / \mathrm{mm}$ and $-0.1691 \mathrm{~N} / \mathrm{mm}$ respectively. This value depicts that the plate allowable deflection of $1 \mathrm{~mm}$ and specified thickness of $5 \mathrm{~mm}$ required maintenance to improve on its structural integrity. 
The value of critical lateral load of the plate at a span of $3000 \mathrm{~mm}$ for allowable deflection $\left(\mathrm{w}_{\mathrm{s}}\right)$ of $1 \mathrm{~mm}$ through $5 \mathrm{~mm}$ is presented. It is observed that at constant $\mathrm{q}_{s}$, value of critical load $\left(\mathrm{q}_{c}\right)$ varied between $-1.0830 \mathrm{~N} / \mathrm{mm}$ and $0.3666 \mathrm{~N} / \mathrm{mm}$ at specified thickness of $5 \mathrm{~mm}$ and $15 \mathrm{~mm}$ (1 $\mathrm{mm}$ and $5 \mathrm{~mm}$ allowable deflection) being the lowest and highest value respectively. The positive value of critical lateral imposed load $\left(q_{s}\right)$ reveals that the plate does not fail in $\mathrm{q}_{s}$ and its value is not affected by change in allowable deflection and thickness of the plate, but only affected by ratio of length and breadth of the plate. Meanwhile, it is shown that failure of critical lateral imposed load $\left(\mathrm{q}_{c}\right)$ occur at all allowable deflection and thickness of the plate. This value depicts that the plate allowable deflection of $1 \mathrm{~mm}, 3 \mathrm{~mm}$ and $5 \mathrm{~mm}$, and specified thickness of $5 \mathrm{~mm}, 10 \mathrm{~mm}, 12.5 \mathrm{~mm}, 15 \mathrm{~mm}$ required maintenance to improve on its structural integrity.

The value of critical lateral load of the plate at a span of $5000 \mathrm{~mm}$ for allowable deflection $\left(\mathrm{w}_{\mathrm{s}}\right)$ of $1 \mathrm{~mm}$ through $5 \mathrm{~mm}$ is presented. It is observed that at constant $\mathrm{q}_{s}$, the value of critical load $\left(\mathrm{q}_{c}\right)$ varied between $-1.1457 \mathrm{~N} /$ $\mathrm{mm}$ and $-0.3826 \mathrm{~N} / \mathrm{mm}$ at specified thickness of $5 \mathrm{~mm}$ and $15 \mathrm{~mm}$ ( $1 \mathrm{~mm}$ and $5 \mathrm{~mm}$ allowable deflection) being the lowest and highest value respectively. The positive value of critical lateral imposed load $\left(q_{s}\right)$ reveals that the plate does not fail in $\mathrm{q}_{s}$ and its value is not affected by the change in the allowable deflection and thickness of the plate, but only affected by the ratio of the length and breadth of the plate. Meanwhile, it is shown that the failure of critical lateral imposed load $\left(q_{c}\right)$ occur at all allowable deflection and thickness of the plate. This value depicts that the plate allowable deflection of $1 \mathrm{~mm}, 3 \mathrm{~mm}$ and $5 \mathrm{~mm}$, and specified thickness of $5 \mathrm{~mm}, 10 \mathrm{~mm}$, $12.5 \mathrm{~mm}, 15 \mathrm{~mm}$ required maintenance to improve on its structural integrity.

At this juncture, it's worthy to note that from the numerical analysis performed for the SSFS plate with a span of $1000 \mathrm{~mm}$ to $5000 \mathrm{~mm}$, at specified thickness of $5 \mathrm{~mm}$ to $15 \mathrm{~mm}$ and length to breadth ratio of 1 to 2 , there is no total structural failure that led to collapse rather a failure that is maintainable is observed. This is because the negative value of critical lateral imposed $\left(q_{c}\right.$ and $q_{s}$ ) reveals that the plate fails in both $q_{c}$ and $q_{s}$ for the all specified deflection which is not recorded in this study. The result of the comparison made as presented in Table 2, Figures 2 and 3, shows that the present study predicts slightly higher values for all aspect ratios. This proves some level safety and reliability of this method as it will not put the structure into danger. The total average percentage difference between the present study and that of Ezeh et al. (2018) is 3862.8\%. This reveals that the work of Ezeh et al (2018), produces error and cannot be reliable for thick plate analysis. This can be proven as the total average percentage difference between the present study and that of Gwarah (2019) is 6.9\%. This means that at about $93 \%$ confidence level, the values from the present study are the same with those of Gwarah (2019). This value has been sufficient in the statistical analysis showed that the present method can be used with confidence for analysis of deflection on a SSFS rectangular plate.

\section{Conclusion}

Application of a new refined shear deformation theory for the analysis of thick rectangular plate has been investigated. From the study this conclusion has been drawn:

i. The values of critical lateral load obtained by this theory achieve accepted vertical shear stress to the thickness of plate variation and satisfied the transverse flexibility of condition of the plate while predicting the bending behavior of an isotropic rectangular SSFS plate. ii. There is no total structural failure that lead to collapse rather a failure that is maintainable is observed in SSFS rectangular plate analysis.

iii. The deflection and stresses obtained by present theory are in good agreement with the other theories. This proved that the present theory is reliable for the analysis of a rectangular plate.

Table 1. Comparison of results from the present work and literature values of square thick rectangular plate

\begin{tabular}{|c|c|c|c|c|c|c|}
\hline B $(\mathrm{a} / \mathrm{t})$ & $\begin{array}{c}\text { Present } \\
(\mathrm{w})\end{array}$ & $\begin{array}{c}\text { Gwarah } \\
(2019) \\
(\mathrm{w})\end{array}$ & $\begin{array}{c}\text { Differe } \\
\text { nce }\end{array}$ & $\begin{array}{c}\text { Present } \\
(\mathrm{w})\end{array}$ & $\begin{array}{c}\text { Ezeh et } \\
\text { al. } \\
(2018) \\
(\mathrm{w})\end{array}$ & $\begin{array}{c}\text { Differe } \\
\text { nce }\end{array}$ \\
\hline 4 & 0.0100 & 0.0093 & 7.1185 & 0.0100 & 0.0003 & 3867.2 \\
\hline 5 & 0.0094 & 0.0088 & 6.9017 & 0.0094 & 0.0002 & 3870.8 \\
\hline 10 & 0.0086 & 0.0080 & 7.6015 & 0.0086 & 0.0002 & 3883.3 \\
\hline 20 & 0.0083 & 0.0078 & 6.7423 & 0.0082 & 0.0002 & 3861.7 \\
\hline 30 & 0.0082 & 0.0077 & 6.7496 & 0.0082 & 0.0002 & 3861.5 \\
\hline 40 & 0.0082 & 0.0077 & 6.7480 & 0.0082 & 0.0002 & 3854.8 \\
\hline 50 & 0.0082 & 0.0077 & 6.7403 & 0.0082 & 0.0002 & 3851.4 \\
\hline 60 & 0.0082 & 0.0077 & 6.7429 & 0.0082 & 0.0002 & 3850.0 \\
\hline 70 & 0.0082 & 0.0077 & 6.7316 & 0.0082 & 0.0002 & 3848.6 \\
\hline 80 & 0.0082 & 0.0077 & 6.7464 & 0.0082 & 0.0002 & 3867.2 \\
\hline 90 & 0.0082 & 0.0077 & 6.7334 & 0.0082 & 0.0002 & 3866.7 \\
\hline 100 & 0.0082 & 0.0077 & 6.7612 & 0.0082 & 0.0002 & 3866.7 \\
\hline CPT & 0.0082 & 0.0077 & 6.7612 & 0.0082 & 0.0002 & 3866.7 \\
\hline $\begin{array}{c}\text { Ave } \\
\%\end{array}$ & & & & & & \\
differ & & 6.9 & & & 3862.8 & \\
\hline
\end{tabular}

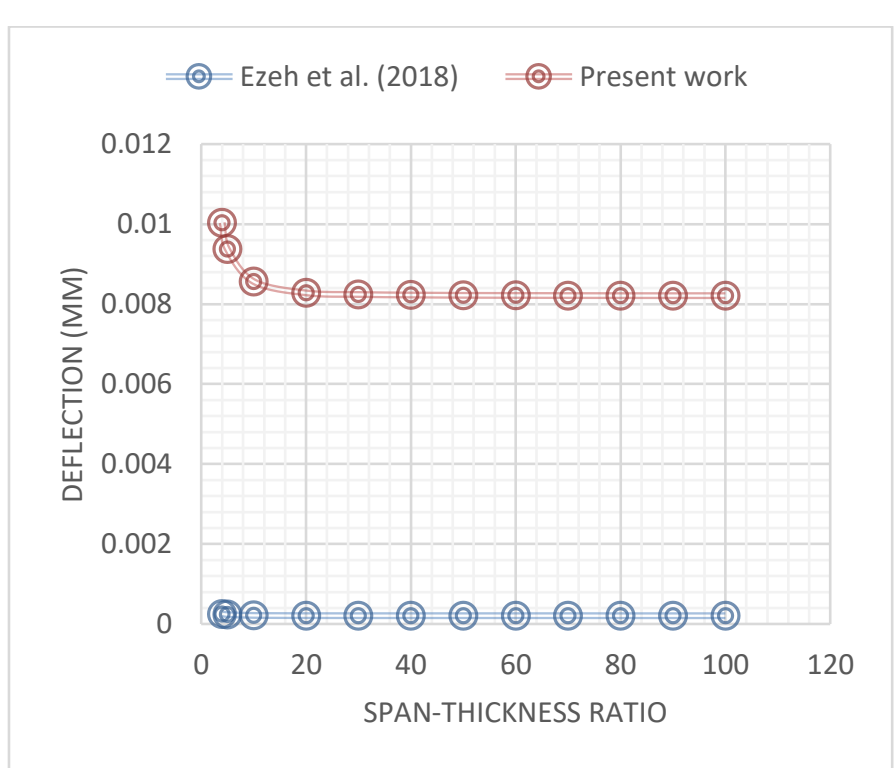

Fig. 2: Graph of deflection versus span to thickness ratio used to compare present work with literature 


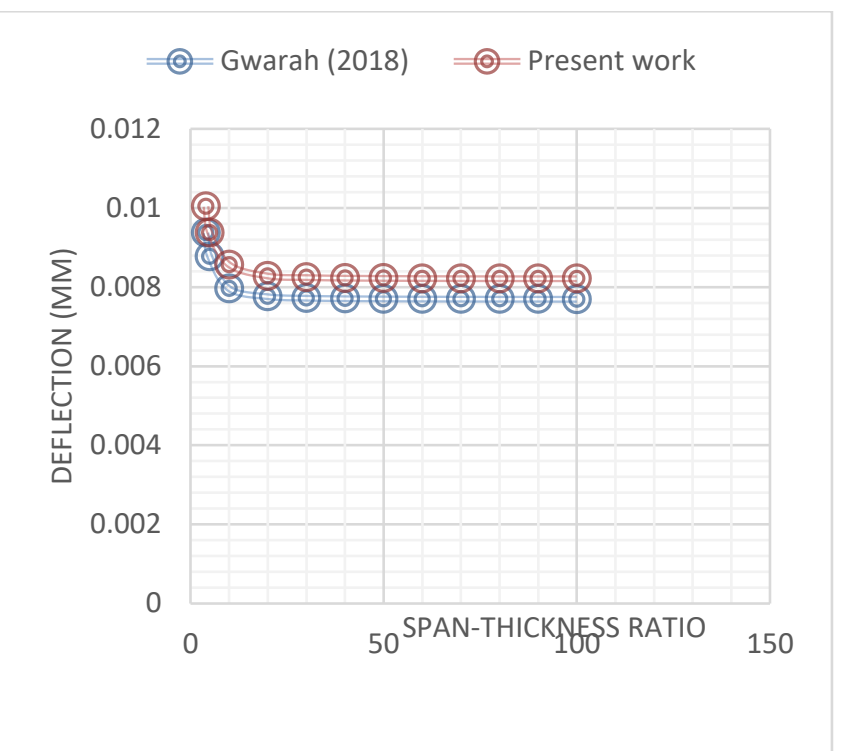

Fig. 3: Graph of deflection versus span to thickness ratio used to compare present work with literature

\section{REFERENCES}

Ezeh, J. C., Ibearugbulem, O. M., Ettu, L. O., Gwarah, L. S., Onyechere, I. C. (2018). Application of Shear Deformation Theory for Analysis of CCCS and SSFS Rectangular Isotropic Thick Plates. Journal of Mechanical and Civil Engineering (IOSRJMCE), 15(5), pp. 33-42.

Ghugal, Y. M., Kulkarni, S. K. (2011). Thermal Stress Analysis of Cross-Ply Laminated Plates Using Refined Shear Deformation Theory. Journal of Experimental and Applied Mechanics, 2, pp. 4766.

Ghugal, Y. M., Sayyad, A. S. (2011). Free Vibration of Thick Isotropic Plates Using Trigonometric Shear Deformation Theory. J. Solid Mech. 3(2), pp. 172-182.

Gwarah, L. S. (2019). Application of Shear Deformation Theory in the Analysis of Thick Rectangular Plates Using Polynomial Displacement Functions. A published PhD. Thesis Presented to the School of Postgraduate Studies in Civil Engineering, Federal University of Technology, Owerri, Nigeria.

Ibearugbulem, O. M., Onyeka, F. C. (2020). Moment and Stress Analysis Solutions of Clamped Rectangular Thick Plate. European Journal of Engineering Research and Science, 5(4), pp. 531534.

Kirchhoff, G. R. (1850). U'ber die Schwingungen einer kriesformigen elastischen Scheibe. Annalen der Physik und Chemie 81, 258-264 (in German).

Mantari, A. S., Oktem, C., Guedes Soares. (2012). A New Trigonometric Shear Deformation Theory for Isotropic, Laminated Composite and Sandwich Plates. Int. J. Solids and Struc, 49, pp. 43-53.

Mindlin, R. D. (1951). Influence of Rotary Inertia and Shear on Flexural Motions of Isotropic, Elastic Plates. ASME Journal Applied Mechanics, 18, pp. 31-38.

Onyeka, F. C. (2019). Direct Analysis of Critical Lateral Load in a Thick Rectangular Plate using Refined Plate Theory. International Journal of Civil Engineering and Technology, 10(5), pp. 492-505.

Onyeka, F. C., Ibearugbulem, O. M. (2020). Load Analysis and Bending Solutions of Rectangular Thick Plate. International Journal on Emerging Technologies, 11(3), pp. 1103-1110.

Onyeka, F. C., Okafor, F. O., Onah, H. N. (2018). Displacement and Stress Analysis in Shear Deformable Thick Plate. International Journal of Applied Engineering Research, 13(11), pp. 9893-9908.

Onyeka, F. C., Okafor, F. O., Onah, H. N. (2019). Application of Exact Solution Approach in the Analysis of Thick Rectangular Plate.
International Journal of Applied Engineering Research, 14(8), pp. 2043-2057.

Onyeka, F. C., Okeke, E. T., Wasiu, J. (2020). Strain-Displacement Expressions and their Effect on the Deflection and Strength of Plate. Advances in Science, Technology and Engineering Systems Journal, 5(5), pp. 401-413.

Okafor, F. O., Udeh, O. T. (2015). Direct Method of Analysis of An Isotropic Rectangular Plate Using Characteristic Orthogonal Polynomials. Nigerian journal of technology, 34(2), pp. 232-239.

Reddy, J. N. (1984). A Refined Non-Linear Theory of Plates with Transverse Shear Deformation. International Journal of Solids and Structures, 20, pp. 881-896.

Reissner, E. (1944). On the Theory of Bending of Elastic Plates. J. Math. Phy, 23, pp. 184-191.

Reissner, E. (1945). The Effect of Transverse Shear Deformation on the Bending Elastic Plate. Transactions of the American Society of Mechanical Engineers, Journal of Applied Mechanics, 12, pp. 69-77.

Sayyad, A. S., Ghugal, Y. M. (2012a). Bending and Free Vibration Analysis of Thick Isotropic Plates by Using Exponential Shear Deformation Theory. Applied and Computational Mechanics, 6(1), pp. 65-82.

Sayyad, A. S., Ghugal, Y. M. (2012b). Buckling Analysis of Thick Isotropic Plates by Using Exponential Shear Deformation Theory. Applied and Computational Mechanics, 6(2), pp. 185-196.

Sayyad, I.I. Chikalthankar, S. B., Nandedkar, V. M. (2013). Bending and Free Vibration Analysis of Isotropic Plate Using Refined Plate Theory. Bonfring International Journal of Industrial Engineering and Management Science, 3(2), pp. 40-46. 